\title{
COMPARATIVE EVALUATION OF FENTANYL VERSUS BUTORPHANOL DURING INDUCTION WITH PROPOFOL ON LMA INSERTION CONDITIONS
}

\author{
Sobha Sukumara Pillai ${ }^{1}$, Jamunarani Jagadamma²
}

${ }^{1}$ Additional Professor, Department of Anaesthesiology, Government Medical College, Trivandrum. ${ }^{2}$ Assistant Professor, Department of Anaesthesiology, Government Medical College, Trivandrum.

\section{ABSTRACT}

\section{BACKGROUND}

Airway management skills constitute the cornerstone of anaesthesiology practice. The introduction of LMA by Dr. Archie Brain has revolutionised airway management of modern general anaesthesia. Propofol when used alone as inducing agent is unsatisfactory to overcome problems associated with LMA insertions.

The aim of the present study was to compare the efficacy of fentanyl and butorphanol as adjuvants to propofol for better LMA insertion conditions.

\section{MATERIALS AND METHODS}

After obtaining Institutional approval and individual consent, forty patients were randomly selected and divided into two groups of twenty each in this randomised control study. In Group F (Fentanyl 1 microgram per kg) was given and in Group B (Butorphanol 20 microgram per $\mathrm{kg}$ ) was given. All the patients were induced with propofol 2.5 milligram per kg. Primary outcome parameter was jaw relaxation assessed using Young's criteria and secondary outcome parameter was overall LMA insertion conditions according to modified scheme of Lund and Stovener.

\section{RESULTS}

The patient characteristics and demographic data were comparable in the two groups. A statistically significant absolute jaw relaxation was observed in Group B (Butorphanol 20 microgram per $\mathrm{kg}$ ) 85\% patients compared to Group $\mathrm{F}$ (Fentanyl 1 microgram per $\mathrm{kg}$ ) $40 \%$ patients. Excellent LMA insertion conditions were observed in $90 \%$ patients in Group B and $55 \%$ of patients in Group F. Top up doses of propofol required and the apnoea time were significantly less in Group B.

\section{CONCLUSION}

Absolute jaw relaxation and excellent LMA insertion conditions with lesser side effects were provided by addition of butorphanol to propofol as compared to fentanyl.

\section{KEYWORDS}

Propofol, Fentanyl, Butorphanol, LMA, Insertion Conditions, Jaw Relaxation.

HOW TO CITE THIS ARTICLE: Pillai SS, Jagadamma J. Comparative evaluation of fentanyl versus butorphanol during induction with propofol on LMA insertion conditions. J. Evolution Med. Dent. Sci. 2017;6(19):1468-1472, DOI: 10.14260/Jemds/2017/322

\section{BACKGROUND}

The major responsibility of an Anaesthesiologist is to provide adequate ventilation to the patient. The wide variety of airway armamentarium available today may be broadly classified as infraglottic and supraglottic airway devices, which are employed to protect airway in both elective and emergency situations. ${ }^{1}$

The LMA was conceived and designed by Dr. Archie Brain in UK in 1981 and following prolonged research it was released in 1988 for clinical use. Today, it has a clearly established role as an airway device in the elective setting where neither the procedure nor the patient requires endotracheal intubation. It is a good alternative to continued bag and mask ventilation and has proved extremely useful in managing the difficult airway.

Laryngeal Mask Airway (LMA) being a supraglottic device has the advantage of being less stimulating than tracheal

Financial or Other, Competing Interest: None.

Submission 27-01-2017, Peer Review 20-02-2017,

Acceptance 26-02-2017, Published 03-03-2017.

Corresponding Author:

Dr. Sobha Sukumara Pillai,

Sai Poorna, MPRA-105 (E), Kalakaumudhi Road,

Murinjapalam, Trivandrum-695011, Kerala.

E-mail: sobhathambu@yahoo.co.in

DOI: $10.14260 /$ jemds $/ 2017 / 322$

\section{(c) $(i) \Theta$}

intubation as visualisation of the vocal cords and entry into the larynx is not required. 2 The LMA insertion technique does not require the use of a Laryngoscope or muscle relaxants. Successful insertion of LMA requires sufficient depth of anaesthesia to relax the jaw and to obtund the airway reflexes to avoid gagging, coughing and laryngospasm. Inadequate depth of anaesthesia may provoke these conditions leading to adverse haemodynamic changes and increased incidence of regurgitation and aspiration. Various induction agents like thiopental and propofol have been studied to achieve excellent LMA insertion conditions.

Propofol is now increasingly being considered as the agent of choice for LMA insertion, because of its depressant effect on laryngeal reflexes compared to other induction agents.3,4,5 However, propofol is expensive and if used alone relatively large doses are required which can cause cardiac depression. ${ }^{6,7}$ Hence, a number of adjuvants were studied for facilitating LMA insertion with Propofol like intravenous midazolam, intravenous lignocaine, clonidine, opioids, lowdose succinylcholine.8,9,10 of these, opioids are most commonly studied. The opioids being narcotic drugs need licensing and require distribution records. Fentanyl is a synthetic opioid related to phenyl piperidines. It is a potent analgesic 80 times more potent than morphine. It possesses other properties of opioids namely sedation, respiratory depression, vagal stimulation, nausea and vomiting. Fentanyl 
can blunt or eliminate somatic and autonomic responses to tracheal intubation. Anaesthesia induction is usually achieved by combining loading dose of 2 - 6 microgram $/ \mathrm{kg}$ of fentanyl along with sedative hypnotic, mostly propofol or thiopental. Studies have been done using different doses of fentanyl as adjuvant to propofol for evaluating LMA insertion conditions. The short-acting and potent opioids like remifentanil and alfentanil are expensive and are not freely available.

Butorphanol being a non-narcotic and non-controlled drug has the advantage of reducing the number of distribution records associated with Schedule II narcotics. Butorphanol is comparatively cheaper drug and is available over the counter. Respiratory depression induced by butorphanol demonstrates a ceiling effect. ${ }^{11,12}$ In addition it was used effectively for conscious sedation. The effect of prior administration of butorphanol in reducing the pain on propofol injection has also been studied.13 Prior studies comparing combination of butorphanol to that of fentanyl as adjuncts to propofol and thiopentone for LMA insertion has been done.14,15,16,17 In this study, we have assessed the jaw relaxation and overall LMA insertion conditions produced by butorphanol-propofol and have compared with propofolfentanyl combination.

\section{MATERIALS AND METHODS}

Approval from Ethics Committee was obtained prior to the start of study. In a population of patients being posted for surgery a pre-anaesthetic checkup was done. From this, the patients who required general anaesthesia with LMA for maintaining anaesthesia were selected based on inclusion and exclusion criteria and according to the weight and physical characteristics. Patients of both genders between the age 18 to 65 years coming under ASA PS I or II were included.

Patients at risk of aspiration, suffering from pathology of neck or upper respiratory tract with poor pulmonary compliance with recorded allergy to propofol, fentanyl or butorphanol and with mouth opening less than $4 \mathrm{~cm}$ were excluded from the study.

The patients selected were invited to take part in the study after explaining the benefits and risks. Informed consent was obtained from those individuals who were willing for the study. The age, weight and airway assessment were done.

\section{The Airway was Assessed According to-}

1. Mallampati classification.

2. The Thyromental distance.

3. The mouth opening - It is measured and assessed as less than or equal to $6 \mathrm{~cm}$ or greater than $6 \mathrm{~cm}$.

The patients were kept nil per orally for 8 hours. The basal heart rate, systolic and diastolic blood pressure were noted. Randomisation was done using a computer generated random number table into Group F (Those who received fentanyl 1 microgram per kilogram as adjuvant to propofol) and Group B (Those who received butorphanol 20 microgram per kilogram as adjuvant to propofol). According to weight of the patient's appropriate size Classic LMA was kept ready. LMA cuff was checked and deflated. A water based jelly was applied over the cuffed portion as per manufacturer regulations. Monitors included Electrocardiogram, Noninvasive blood pressure and Pulse-oximeter.
All patients were premeditated with midazolam $0.02 \mathrm{mg}$ per $\mathrm{kg}$ and glycopyrrolate $0.2 \mathrm{mg}$ intravenously. They were preoxygenated with $100 \%$ oxygen for three minutes. Then they were given the assigned drugs over 10 seconds. The patients in Group $\mathrm{F}$ received fentanyl 1 microgram per kilogram intravenously and those in Group B received butorphanol 20 microgram per kilogram intravenously. Anaesthesia was induced with Inj. Propofol $2.5 \mathrm{mg}$ per $\mathrm{kg}$ intravenously over a period of 15 seconds. Whenever needed, incremental doses of propofol $0.5 \mathrm{mg}$ per kg were given every 30 seconds till loss of consciousness and loss of eye lash reflex was achieved. Sixty seconds later LMA insertion was performed by a blinded observer. Patients were given additional doses of $0.5 \mathrm{mg}$ per $\mathrm{kg}$ on every unsuccessful attempt. The jaw relaxation and overall LMA insertion conditions were graded at the first attempt only.

LMA insertion was attempted for a maximum of 3 times. Patients were then kept on spontaneous respiration. Anaesthesia was maintained with $0.75 \%$ to $1 \%$ Halothane with nitrous oxide $60 \%$ and oxygen $40 \%$. Heart rate and noninvasive blood pressure were recorded pre-induction, immediately after induction of anaesthesia and after insertion of LMA. ECG monitoring was done to record any arrhythmias. Continuous pulse oximeter monitoring was done during surgery. Non-invasive blood pressure was monitored every ten minutes. At the completion of surgery, halothane and nitrous oxide were stopped and LMA was removed and 100\% oxygen with face mask was continued till recovery.

\section{Following Parameters were Observed during Insertion of} LMA -

Jaw Relaxation was Assessed according to Young's Criteria. This was assessed on a Three-Point Scale

1. Absolutely relaxed with no muscle tone.

2. Moderately relaxed with some muscle tone.

3. Poorly relaxed with full muscle tone.

Coughing and Gagging - This was Assessed on a FourPoint Scale

1. No coughing or gagging.

2. Mild coughing, gagging.

3. Moderate coughing, gagging.

4. Severe coughing, gagging.

Laryngospasm was Assessed on Two-Point Scale

1. No laryngospasm.

2. Laryngospasm.

Patient Movements were Assessed on a Three-Point Scale

1. No movement.

2. Mild movement.

3. Severe movement.

The overall LMA insertion condition was assessed according to modified scheme of Lund and Stovener.

Excellent - No coughing or gagging, no patient movement or laryngospasm.

Good - Mild gagging, coughing or mild patient movement with no laryngospasm.

Poor - Moderate gagging, coughing or mild patient movement with no laryngospasm.

Unacceptable - Severe gagging, coughing or severe patient movement or laryngospasm. 
Top-up dose of propofol required or not.

Total dose of propofol required.

Duration of apnoea.

The data from the study was systematically collected, compiled and statistically analysed to draw relevant conclusions. Data was analysed using computer software, statistical package for social sciences version 10. Primary objective was calculated using Fisher Exact test. The level of significance is 0.05 .

\section{RESULTS}

There were no significant differences between the two groups with respect to demographic data, anthropometric data and ASA PS status (Table 1).

\section{Jaw Relaxation}

In our study, comparison of jaw relaxation between Groups $\mathrm{F}$ and B was considered as primary objective. Grade I jaw relaxation was seen in $40 \%$ of patients in Group $\mathrm{F}$ and $85 \%$ of the patients in Group B. P value was 0.004 , which was significant (Table 2).

\section{Coughing/Gagging}

In our study $10 \%$ of the patients in Group B had mild coughing or gagging, while $45 \%$ in Group $\mathrm{F}$ had mild coughing or gagging. No patients had severe coughing. $\mathrm{P}$ value is 0.015 , which is significant (Table 3 ).

\section{Patient Movements}

The rate of mild patient movement in Group B was 15\% and that of Group F was 50\%. There were no severe patient movements during the study. $P$ value is 0.02 , which is statistically significant (Table 4).

\section{Laryngospasm}

Laryngospasm was observed in $15 \%$ of patients who received fentanyl as adjuvant. There was no laryngospasm in B Group. $P$ value is 0.115 and not significant (Table 5).

\section{LMA Insertion Conditions}

In Group F 55\% patients had excellent LMA insertion conditions, while $90 \%$ of the patients had excellent insertion conditions in Group B. P value 0.015, which was significant (Table 6).

\section{Top-Up Dose of Propofol}

$30 \%$ of patients in Group F required top-up dose of propofol; $5 \%$ of patients in Group B needed top up. $\mathrm{P}$ value was $0.046 \%$, which was significant (Table 7).

\section{Total Dose of Propofol}

Mean total dose of propofol required in Group B was 140.6 +/- $18.6 \mathrm{mg}$ and in Group F was 149.7 +/- $29.8 \mathrm{mg}$. P value was 0.256 , which was insignificant.

\section{Duration of Apnoea}

The mean duration of apnoea in Group F was $44.5+$ +- 16.4 seconds and that in Group B was $31.5+/-6.9$ seconds. P value is 0.002 , which is significant (Table 8).

\section{DISCUSSION}

Induction agents like propofol, which reduced pharyngeal and laryngeal reflexes has drastically altered the scenario of airway management with LMA. Although comparatively safe, a higher dose of propofol is required for suppressing airway reflexes. This causes significant cardiac depression. To reduce this depressant effect, many adjuvant drugs have been tried till date of which we compared fentanyl and butorphanol. In our study, comparison of jaw relaxation between Group F and B was considered as primary objective. Grade I jaw relaxation was seen in $40 \%$ of patients in Group $\mathrm{F}$ and $85 \%$ of the patients in Group B. This finding in our study is supported by the study conducted by Gupta A and Kaur S in 201118; (93.3\% absolute jaw relaxation in propofol butorphanol group vs. $53.33 \%$ in propofol fentanyl group).

$90 \%$ of patients in Group B and 55\% of the patients in Group $\mathrm{F}$ had no cough or gagging. Decreased gagging in butorphanol group is probably due to the antitussive action and limited skeletal muscle action of butorphanol. This finding is supported by the study conducted by Gupta A and Kaur S et al in 2011. (43.33\% coughing in fentanyl group vs $13.33 \%$ coughing in butorphanol group) and also in the study conducted by Wong $\mathrm{C} \mathrm{M}$ et $\mathrm{al}, 19$ in which higher doses of fentanyl were associated with increased incidence of coughing. Increased incidence of gagging in Group F can be due to the administration of bolus dose of intravenous fentanyl. El Baissan M C et al in 2014 suggested the reason of cough during bolus administration of fentanyl may be due to several reasons including inhibition of central sympathetic system leading to vagal predominance, reflex bronchoconstriction after stimulating tracheobronchial tree or histamine release. 20

The rate of mild patient movement in Group B was 15\% and that of Group $\mathrm{F}$ was $50 \%$. There was no severe patient movement during the study. This is also consistent with the study conducted by Gupta A and Kaur S et al in 2011.

In Group F 55\% patients had excellent LMA insertion conditions, while $90 \%$ of the patients had excellent insertion conditions in Group B. Chari P and Ghai B et al compared the LMA insertion conditions provided by butorphanol 30 microgram per kg and fentanyl 1.5 microgram per kg with thiopentone as induction agent and concluded that butorphanol thiopentone combination provided excellent LMA insertion conditions compared to fentanyl thiopentone group ( $98 \%$ vs. $86 \%$ success rate with $92 \%$ vs. $71 \%$ ease of insertion).

$30 \%$ of patients in Group $\mathrm{F}$ required top-up dose of propofol and 5\% of patients in Group B needed topup. This finding is consistent with the study conducted by Gupta A and Kaur S.

In our study the mean total dose of propofol required in the group, which received propofol with butorphanol was $140.6+/-18.6 \mathrm{mg}$ and that in the group which received propofol with fentanyl was $149.7+/-29.8 \mathrm{mg}$. The $\mathrm{p}$ value was 0.256 . The value is insignificant. Gupta A and Kaur S in 2011 compared the mean total dose of propofol required for LMA insertion in 90 patients who were given Propofol and Fentanyl, Propofol with Butorphanol and Propofol with Ketamine. The mean total dose of propofol required was $140.08+/-18.97 \mathrm{mg}$ in the group which received butorphanol and it was $156.22+/-17.18 \mathrm{mg}$ in the group which received Fentanyl. $P$ value was significant in their study. 
The mean duration of apnoea in Group $\mathrm{F}$ was 44.5 +/16.4 seconds and that in Group B was 31.5 +/- 6.9 seconds. This difference is due to differential action of butorphanol on $\mathrm{mu}$, kappa and delta opioid receptors. This is consistent with the study conducted by Cheam E W S and Chui P T,21 which found that fentanyl prolongs duration of apnoea when used along with propofol for LMA insertion.

From this randomised, controlled trial comparing LMA insertion conditions provided by fentanyl versus butorphanol with propofol as induction agent, it can be concluded as follows -

1. Addition of butorphanol to propofol can provide better jaw relaxation and excellent LMA insertion conditions.

2. Lower top-up dose of propofol is needed in butorphanol group.

3. Lower duration of apnoea will be produced by butorphanol.

Hence, butorphanol can be considered superior to fentanyl as an adjuvant to propofol for insertion of LMA.

\begin{tabular}{|c|c|c|c|}
\hline & $\begin{array}{c}\text { Group B } \\
(\mathbf{n = 2 0})\end{array}$ & $\begin{array}{c}\text { Group F } \\
(\mathbf{n = 2 0})\end{array}$ & $\begin{array}{c}\text { P } \\
\text { value }\end{array}$ \\
\hline $\begin{array}{c}\text { Age (Years) } \\
\text { Mean +/- S.D. }\end{array}$ & $34.5+/-7.5$ & $32.6+/-6.8$ & 0.409 \\
\hline $\begin{array}{c}\text { Sex } \\
\text { Male/Female }\end{array}$ & $6 / 14$ & $6 / 14$ & 0.634 \\
\hline $\begin{array}{c}\text { Weight (kg) } \\
\text { Mean +/-S.D. }\end{array}$ & $55.8+/-7.5$ & $55.6+/-6.3$ & 0.946 \\
\hline $\begin{array}{c}\text { ASAPS } \\
\text { I/II }\end{array}$ & $16 / 4$ & $17 / 3$ & 0.500 \\
\hline \multicolumn{4}{|c|}{ Table 1. Demographic Data } \\
\hline
\end{tabular}

\begin{tabular}{|c|c|c|c|c|c|}
\hline \multicolumn{4}{|c|}{ Comparison of Jaw Relaxation Based on Group } \\
\hline \multirow{2}{*}{$\begin{array}{c}\text { Jaw } \\
\text { Relaxation }\end{array}$} & \multicolumn{2}{|c|}{ Group F } & \multicolumn{2}{c|}{ Group B } & P \\
\cline { 2 - 5 } value \\
\hline Grade I & 8 & 40 & 17 & 85 & \\
\hline Grade II & 12 & 60 & 3 & 15 & \\
\hline \multicolumn{5}{|c|}{ Table 2. Jaw Relaxation } \\
\hline
\end{tabular}

\begin{tabular}{|c|c|c|c|c|c|}
\hline \multicolumn{6}{|c|}{ Comparison of Coughing, Gagging Based on Group } \\
\hline \multirow{2}{*}{$\begin{array}{l}\text { Coughing and } \\
\text { Gagging }\end{array}$} & \multicolumn{2}{|c|}{ Group F } & \multicolumn{2}{|c|}{ Group B } & \multirow{2}{*}{$\begin{array}{c}P \\
\text { value }\end{array}$} \\
\hline & Count & $\%$ & Count & $\%$ & \\
\hline Grade I & 11 & 55 & 18 & 90 & \multirow{2}{*}{0.015} \\
\hline Grade II & 9 & 45 & 2 & 10 & \\
\hline \multicolumn{6}{|c|}{ d Gaggi } \\
\hline
\end{tabular}

\begin{tabular}{|c|c|c|c|c|c|}
\hline \multicolumn{3}{|c|}{ Comparison of Patient Movements Based on Group } \\
\hline \multirow{2}{*}{ Movements } & Group F & \multicolumn{2}{c|}{ Group B } & P \\
\cline { 2 - 5 } & Count & $\mathbf{\%}$ & Count & $\mathbf{\%}$ & value \\
\hline Grade I & 10 & 50 & 17 & 85 & \multirow{2}{*}{0.02} \\
\hline Grade II & 10 & 50 & 3 & 15 & \\
\hline \multicolumn{7}{|c|}{ Table 4. Patient Movement } \\
\hline
\end{tabular}

\begin{tabular}{|c|c|c|c|c|c|}
\hline \multicolumn{7}{|c|}{ Comparison of Laryngospasm based on Group } \\
\hline \multirow{2}{*}{ Laryngospasm } & Group F & Group B & P \\
& Count & $\%$ & Count & $\%$ & value \\
\hline Grade I & 17 & 85 & 20 & 100 & \multirow{2}{*}{0.115} \\
\hline Grade II & 3 & 15 & 0 & 0 & \\
\hline Table 5. Laryngospasm \\
\hline
\end{tabular}

\begin{tabular}{|c|c|c|c|c|c|}
\hline \multicolumn{5}{|c|}{$\begin{array}{c}\text { Comparison of Overall LMA Insertion } \\
\text { Conditions based on Group }\end{array}$} \\
\hline LMA Insertion & \multicolumn{2}{|c|}{ Group F } & Group B & P \\
Condition & Count & $\%$ & Count & $\%$ & value \\
\hline Excellent & 11 & 55 & 18 & 90 & \\
\hline Good & 9 & 45 & 2 & 10 & \\
\hline \multicolumn{7}{|c|}{ Table 6. Overall LMA Insertion Conditions } \\
\hline
\end{tabular}

\begin{tabular}{|c|c|c|c|c|c|}
\hline \multicolumn{6}{|c|}{ Comparison of Top-Up Dose of Propofol based on Group } \\
\hline \multirow{2}{*}{$\begin{array}{c}\text { Top- } \\
\text { Up }\end{array}$} & \multicolumn{2}{|c|}{ Group F } & \multicolumn{2}{c|}{ Group B } & P \\
\cline { 2 - 5 } value \\
\hline Yes & 6 & 30 & 1 & 5 & \multirow{2}{*}{0.046} \\
\hline No & 14 & 70 & 19 & 95 & \\
\hline \multicolumn{6}{|c|}{ Table 7. Top-Up Dose of Propofol } \\
\hline
\end{tabular}

\begin{tabular}{|c|c|c|c|c|c|}
\hline \multicolumn{2}{|c|}{ Comparison of Duration of Apnoea based on Group } \\
\hline Type & Mean & SD & N & T & P value \\
\hline Group F & 44.5 & 16.4 & 20 & \multirow{2}{*}{$3.28^{* *}$} & \multirow{2}{*}{0.002} \\
\hline Group B & 31.5 & 6.9 & 20 & & \\
\hline \multicolumn{7}{|c|}{ Table 8. Duration of Apnoea } \\
\hline
\end{tabular}

\section{Acknowledgements}

We are greatly indebted to Dr. R. S. Usha Devi, Professor and Head, Department of Anaesthesiology, Government Medical College, Thiruvananthapuram, for the creative suggestions, timely advice and constant encouragement.

We extend our sincere thanks to Dr. Anjana Menon and all our colleagues in their help and support during this study.

We also acknowledge our thanks to the operating room technicians and nurses for their warm and kind cooperation.

We would like to thank all our patients without whom this study would not have materialised.

We sincerely thank Mrs. Athira Rani and Dr. Oommen P Mathew for their immense help in completing the statistical analysis.

Above all we thank God, the Almighty under whose divine guidance, we have been able to complete this work.

\section{CONCLUSION}

From this randomised controlled trial comparing LMA insertion conditions provided by fentanyl versus butorphanol with propofol as induction agent, it can be concluded as follows:

1. Addition of butorphanol to propofol can provide better jaw relaxation and excellent LMA insertion conditions.

2. Lower top-up dose of propofol is needed in butorphanol group.

3. Lower duration of apnoea will be produced by butorphanol.

Hence, butorphanol can be considered superior to fentanyl as an adjuvant to propofol for insertion of LMA.

\section{REFERENCES}

[1] Gal TJ. Airway management. In: Miller RD, ed. Textbook of anaesthesia. $6^{\text {th }}$ edn. Philadelphia: Elsevier 2005:1617-52.

[2] Lamb K, James MF, Janicki PK. The laryngeal mask airway for intraocular surgery: effects on intraocular pressure and stress responses. $\mathrm{Br} \mathrm{J}$ Anaesth 1992;69(2):143-7. 
[3] Brown GW, Patel N, Ellis FR. Comparison of propofol and thiopentone for laryngeal mask insertion. Anaesthesia 1991;46(9):771-2.

[4] Brown GW, Ellis FR. Comparison of propofol and increased dose of thiopentone for laryngeal mask insertion. Acta Anaesthesiol Scand 1995;39(8):1103-4.

[5] Acalovschi I, Miclescu A, Bugov L. The effects of propofol on laryngeal reactivity and the hemodynamic response to laryngeal mask insertion. Eur J Anaesthesiol 1995;12(4):351-6.

[6] Lindgren L, Yli-Hankala A, Randell T, et al. Haemodynamic and catecholamine responses to induction of anaesthesia and tracheal intubation: comparison between propofol and thiopentone. $\mathrm{Br} \mathrm{J}$ Anaesth 1993;70(3):306-10.

[7] Scanlon P, Carey M, Power M, et al. Patient response to Laryngeal mask insertion after induction of anaesthesia with propofol or thiopentone. Can J Anaesth 1993;40(9):816-8.

[8] Yoshino A, Hashimoto Y, Hirashima J, et al. Low-dose succinylcholine facilitates laryngeal mask airway insertion during thiopental anaesthesia. Br J Anaesth 1999;83(2):279-83.

[9] Salem WT. A comparison of midazolam and mini dose succinylcholine to aid laryngeal mask airway insertion during propofol anaesthesia. J Egyptian Nat Cancer Inst 2000;12(1):65-9.

[10] Goyagi T, Tanaka M, Nishikawa T. Oral clonidine premedication reduces propofol requirement for laryngeal mask airway insertion. Can J Anaesth 2000;47(7):627-30.

[11] Vogelsang J, Hayes SR. Butorphanol tartrate (stadol): a review. J Post Anaesth Nurs 1991;6(2):129-35.

[12] Talbert RL, Peters J, Sorrels SL, et al. Respiratory effects of high-dose butorphanol. Acute Care 1988;12 Suppl 1:47-56.
[13] Agarwal A, Raza M, Dhiraaj S, et al. Pain during injection of propofol: the effect of prior administration of butorphanol. Anaesth Analg 2004;99(1):117-9.

[14] Chari P, Ghai B. Comparison of butorphanol and thiopentone vs fentanyl and thiopentone for laryngeal mask airway insertion. J Clin Anaesth 2006;18(1): 8-11.

[15] Goyagi T, Tanaka M, Nishikawa T. Fentanyl decreases propofol requirement for laryngeal mask airway insertion. Acta Anaesthesiol Scand 2003;47(6):771-4.

[16] Day OLI, Nespeca JA, Rinngold C, et al. Outpatient sedation for oral surgery: a comparison of butorphanol and fentanyl. Acute Care 1986;12 (Suppl 1):63-9.

[17] Philip BK, Scott DA, Freiberger D, et al. Butorphanol compared with fentanyl in general anaesthesia for ambulatory laparoscopy. Can J Anaesth 1991;38(2):183-96.

[18] Gupta A, Kaur S, Attri JP, et al. Comparative evaluation of ketamine propofol, fentanyl-propofol and butorphanol-propofol on hemodynamics and laryngeal mask airway insertion conditions. J Anaesthsiol Clin Pharmacol 2011;27(1):74-8.

[19] Wong CM, Critchley LA, Lee A, et al. Fentanyl doseresponse curves when inserting LMA Classic laryngeal mask airway. Anaesthesia 2007;62(7):654-60.

[20] El Baissan MC, Taha SK, Siddik-Sayyid SM. Fentanyl induced cough--pathophysiology and prevention. Middle East J Anaesthesiol 2014;22(5):449-56.

[21] Cheam EW, Chui PT. Randomized double-blind comparison of fentanyl, mivacurium or placebo to facilitate laryngeal mask airway insertion. Anaesthesia 2000;55(4):323-6. 